\title{
Effects of Child Center Care Teachers' Perceived Emotional Support on Burnout Mediated by Basic Psychological Needs
}

\author{
Yun Ok Choi ${ }^{1}$, Ha Young Min ${ }^{2}$ \\ Ph. D. Student, Department of Child Studies, Daegu Catholic University, Gyeongbuk, Korea ${ }^{1}$ \\ Professor, Department of Child Studies, Daegu Catholic University, Gyeongbuk, Korea ${ }^{2}$ \\ 보육교사의 지각된 정서적 지지가 기본심리욕구를 매개로 소진에 미치는 영향 \\ 최윤옥, 민하영 ${ }^{2}$ \\ 대구가톨릭대학교 아동학과 박사과정생 ${ }^{1}$ 대구가톨릭대학교 아동학과 교수 ${ }^{2}$
}

\begin{abstract}
Objectives: The purpose of this study was to investigate the relationship between childcare center teac teachers' level of perceived emotional support and burnout, and to determine if this relationship is mediated by basic psychological needs.

Methods: The participants were 228 teachers working at childcare centers in the Daegu and Gyeongbuk Province. Self-reported questionnaires were used to measure teacher burnout, perceived emotional support, and basic psychological needs.

Results: The data were analyzed using Structural Equation Modeling (SEM). The level of burnout among was found to be negatively influenced by perceived emotional support and basic psychological needs. Perceived emotional support had a positive influence on basic psychological needs; the higher the perception of emotional support, the greater the positive influence on basic psychological needs. While perceived emotional support had a negative influence on burnout, this influence was indirect and was mediated through the basic psychological needs of the childcare teachers.

Conclusion: The findings suggest that it is more useful to strengthen basic psychological needs, than to increase perceived emotional support, for preventing and reducing burnout among childcare teachers.
\end{abstract}

Keywords: child care teacher burnout, emotional support, basic psychological needs

\section{Introduction}

최근 보조교사 및 대체교사를 어린이집에 추가 지원하는 등 보육교사의 처우개선과 보육 환경 개선 사업이 국가적 차원에 서 이루어지고 있다. 그러나 무상보육 전면 실시, 어린이집 평 가인증 제도 의무화, 부모 모니터링 제도, 보육교직원 자격관 리 강화 등이 보육현장에 요구되면서 보육교사의 업무 강도는

Corresponding Author: Hayoung Min, Professor, Department of Child Studies, Daegu Catholic University, Hayang-Ro 13-13, Hayang-Eup, Gyeongsan-Si, Gyeongbuk, Korea Hayang-Eup,Gyeongsan-Si, Gyeongbuk, Korea

E-mail: hymin@cu.ac.kr
향상되어 가고 있다. 보육교사에게 기대되는 높은 업무 강도 는 보육의 질을 향상시킬 수 있는 견인적 과정으로 평가될 수 있으나 다른 한편에서는 보육교사의 직무 소진을 불러일으킴 으로써 내실 있는 보육 활동을 어렵게 만들 수 있다.

Freudenberger (1974)에 의해 제안된 소진은 직무에 대해 탈 진된 심리적 상태를 의미하는 것으로 직무 활동에서 형성된 정 서적 피로(emotional exhaustion), 비인간화(depersonalization) 그

(C) The Korean Association of Child Studies

This is an Open Access article distributed under the terms of the Creative Commons Attribution Non-Commercial License (http:// creativecommons.org/licenses/by-nc/4.0) which permits unrestricted noncommercial use, distribution, and reproduction in any medium, provided the original work is properly cited. 
리고 성취감 상실 상태(personal accomplishment)를 포괄적으로 나타내는 개념이다. 이러한 소진은 업무 전념을 방해하고 주 변 사람들에게 냉소적 태도를 보이게 하며 업무 의욕을 저하시 켜 목표 달성에 어려움을 갖게 만든다. 소진이 업무에 미치는 부정적 영향 때문에 국가 차원에서는 보조교사 및 대체교사 제 도 마련을 통해 보육교사의 소진을 예방하기 위해 노력하고 있 으며, 학계 차원에서는 소진이 보육현장에 미치는 영향을 파악 (Park \& Song, 2019)하거나 소진에 영향을 미치는 변인을 규명 하려는 연구(Y.-Y. Choi \& Shim, 1999; Kim, 2003; Kwon, Chung, \& Park, 2013; S.-J. Oh \& Choi, 2016) 등을 통해 소진 예방이나 해결에 필요한 정보와 자료를 제공하는데 노력하고 있다.

보육교사의 소진 특히 심리적 소진에 영향을 미치는 변인 가 운데 보육교사가 지각하는 정서적 지지는 보육교사의 소진을 보호하거나 예방하는데 유용한 환경적 변인으로 제안(Joung, Choi, \& Lee, 2013; Min, 2010; Song, 2015)되고 있다. 정서적 지 지는 역경이나 어려움 등 스트레스가 높은 상황에서 그로 인한 부정적 영향을 완화시키는 강력한 중재요인으로 알려진 사회 적 지지 개념(Cobb, 1976; Dubow \& Tisak, 1989)의 하위 변인이 다. 사회적 관계 속에서 타인으로부터 제공받는 긍정적 자원을 사회적 지지라고 할 때(Cohen \& Hoberman, 1983), 사회적 지지 는 상황과 대상, 지지의 공급자와 수요자에 따라 다양한 모양 과 속성을 갖는 것으로 알려져 있다(Cohen \& Hoberman, 1983; House, 1981; Thoits, 1982). 그러므로 사회적 지지를 하나의 통일 된 구성 개념으로 제안하는 것은 쉽지 않다. 그러나 일반적으로 사회적 지지는 정서적 지지, 정보적 지지, 평가적 지지, 물질적 지지 등으로 구분되고 있다. 직면한 문제를 해결하는데 도움이 되는 정보나 충고, 조언 등을 제공해 주는 정보적 지지나 자신 감을 고취시키는데 도움을 제공해 주는 평가적 지지 또는 문제 해결에 필요한 물건이나 도구 또는 경제적 지원을 제공해 주는 물질적 지지보다 애정, 소속감, 자존심 등의 정서적 공감과 사 랑, 존중을 표현하는 정서적 지지는 보육교사의 직무 관련 어려 움을 가장 많이 완충해주는 사회적 지지로 알려져 있다(Joung et al., 2013; Min, 2010; Song, 2015). 사회적 지지 중 정서적 지지 가 보육교사에게 강조되는 것은 업무 특성 상 대인 관계를 중심 으로 사회 정서적 상호작용이 주요하게 다루어지기 때문으로 보여진다. 정서적 지지의 중요성을 고려해 볼 때 동료 교사나 원장 또는 학부모로부터의 정서적 공감이나 지원 등은 보육 업 무에서 발생되는 소진을 예방하거나 낮추는데 필요한 주요 환 경적 변인이라 할 수 있다.

그러나 여기서 고려할 점은 정서적 지지가 보육교사가 경 험하는 어려움과 곤란 또는 스트레스로 인한 심리적 부적응을
완충 또는 중재한다고는 하지만 사회적 관계로부터 제공된 애 정, 이해, 수용 등을 보육교사가 지각한다는 사실만으로 심리 적 부적응 문제가 완화 또는 중재될 수 있는가 하는 것이다. 환 경으로부터 제공되는 정서적 지지보다 더 중요한 것은 정서적 지지에 의해 활성화되는 개인적 변인일 수 있기 때문이다. 정 서적 지지 역시 제공되는 객관적 양보다 개인의 주관적 인식 이 사회적 적응을 예측하는데 더 중요하게 인정된다는 사실을 생각해 볼 때, 보육교사의 소진 문제에서 사회적 환경으로부 터의 정서적 지지 외에 정서적 지지 지각에 영향을 미칠 보육 교사의 개인 내적 특성에 주목할 필요가 있다.

정서적 지지와 보육교사의 소진에 관한 연구가 완화 또는 중재적 측면에서 조절 효과에 초점을 두고 연구되어 왔다면, 이 연구에서는 환경으로부터 제공되는 정서적 지지의 조절 효 과보다 정서적 지지가 심리적 적응 문제에 영향을 미칠 때 개 입되는 개인 내적 변인 탐색에 초점을 두고자 한다. 동료 교 사나 학부모 등 사회적 관계로부터 제공되는 정서적 지지도 그것을 어떻게 수용하고 지각하느냐 하는 개인적 역량에 의 해 달라진다는 점을 고려해 볼 때, 지각된 정서적 지지에 의 해 영향받는 보육교사의 소진 역시 보육교사 자신의 개인 내 적 특성에 의해 영향받을 것으로 보여진다. 이러한 점을 고려 해 볼 때 보육교사의 소진에 영향을 미치는 개인 내적 변인으 로 기본심리욕구(basic psychological needs)가 있다. 기본심리 욕구는 자신의 삶을 스스로 통제하고 결정하려는 인간의 주 체적 성향을 설명하는 Deci와 Ryan (1985)의 자기결정성 이론 (Self-Determination Theory [SDT])에서 강조된 개념이다(Deci \& Ryan, 2000; Ryan, Connell, \& Deci, 1985). 기본심리욕구는 인간이 효율적으로 기능하기 위해 충족되어야 하는 필수적 욕 구로 행동 주도를 의미하는 '자율성', 통제감을 나타내는 '유능 성', 사회적 연결감을 의미하는 '관계성'의 3가지 욕구를 말한 다(Ryan \& Deci, 2000). Deci와 Ryan (1985)은 이러한 3가지 기 본심리욕구 때문에 인간은 외적 동기가 없는 상황에서도 자율 적으로 자신의 행동을 결정하고 통제하며 스스로 목표를 달 성하려는 경향성을 보인다고 했다. 실질적으로 기본심리욕 구가 큰 사람은 목표와 행동을 스스로 결정하고, 직면한 환경 에서 최적으로 도전을 시도하거나 숙달하려는 경향이 크다 (Ryan \& Deci, 2000). 뿐만 아니라 주변 사람들과의 정서적 유 대를 형성하려는 성향이 크기 때문에 타인을 배려하거나 관심 을 보이는 등 사회적 관계망 내 사람들과 우호적 관계를 형성 하려 한다. 따라서 구성원과의 갈등을 통해 심리적 소외감이 나 우울감을 경험하는 경우가 적다. 기본심리욕구가 갖는 이 러한 특성 때문에 기본심리욕구가 잘 충족된 교사나 학교 상 
담자의 경우 심리적 소진이 낮으며(S. Choi, 2015; Ford, Olsen, Khojasteh, Ware, \& Urick, 2019; H.-H. Lee \& Hong, 2018), 회 사원의 경우 낮은 불안감과 높은 직업몰입 또는 낮은 직무 소 진을 보고(Deci et al., 2001; H. Oh, Lee, \& Kim, 2019)하고 있다. 이와 같은 사실은 학교 교사나 상담자와 같이 보육교사의 소 진도 교사자신의 개인 내적 특성인 기본심리욕구에 의해 설명 될 수 있음을 의미하는 것이다.

한편 자기결정성의 기본심리욕구는 사회적 관계를 통해 제 공되는 사회적 지지에 긍정적 영향을 받는 것으로 보고되고 있다(Ryan \& Solky, 1996; Soenens \& Vansteenkiste, 2005; Yoon, 2015). 자율성, 유능성, 관계성의 3가지 욕구가 인간이 지니는 기본욕구라 해도 사회적 환경 요소에 의해 기본욕구의 작동과 충족이 영향받기 때문이다. 사회적 관계망에서 제공되는 지지 와 격려는 주변으로부터 사랑받고 인정받고 있다는 느낌을 갖 게 만든다. 그리고 이러한 느낌은 자율성이나 유능감, 특히 관 계성의 기본심리욕구를 충족시킴으로써 자기 스스로 자신의 행동을 결정(self-determination)할 수 있게 한다. 고등학생을 대 상으로 한 연구에서 기본심리욕구는 부모나 또래의 사회적 지 지에 의해 정적 영향을 받는 것(Yoon, 2015)으로 나타났으며 예비유아교사를 대상으로 한 연구에서도 정서적 지지를 포함 한 사회적 지지가 자기결정성의 기본심리욕구와 정적 상관관 계를 나타내고 있음이 보고(M.-S. Choi, 2009)되었다. 사회적 지지와 자기결정성의 기본심리욕구 간 관계에 관한 선행 연구 를 고려해 볼 때, 동료나 원장 등 직장 내 어린이집에서 지각되 는 정서적 지지는 인정과 존중의 기본심리욕구를 충족시킴으 로써 보육교사 스스로 보육교사에게 기대되는 사회적 역할을 적극적이고 성공적으로 수행하도록 내적 동기화한다. 따라서 사회적 관계망으로부터 정서적 지지를 높이 지각하는 보육교 사는 기본심리욕구의 충족으로 인해 자기결정성에 의한 내적 동기를 기반으로 업무를 수행하기 때문에 소진이 낮을 수 있 다. 이는 정서적 지지와 소진 간 관계에서 기본심리욕구가 매 개역할을 수행함을 의미하는 것이다. 실질적으로 기본심리욕 구는 초심 상담자의 심리적 소진에 미치는 성인애착의 영향을 매개(H.-S. Lee \& Lee, 2011)하고 있으며 교사의 소진에 미치는 사회적 지지의 영향도 매개하는 것(S. Choi, 2015)으로 나타나 고 있다. 뿐만 아니라 벨기에 근로자를 대상으로 한 연구(Van den Broeck, Vansteenkiste, De Witte, \& Lens, 2008)에서도 기본 심리욕구는 직무환경이 소진에 미치는 영향을 매개하는 것으 로 나타났다. 이에 이 연구에서는 보육교사의 소진에 미치는 영향을 환경 외적 변인인 사회적 관계망으로부터 지각되는 정 서적 지지와 개인 내적 변인인 기본심리욕구를 중심으로 살펴
보되, 구조모형을 토대로 소진에 미치는 사회적 관계망으로부 터의 정서적 지지의 영향을 기본심리욕구가 매개하는지를 연 구문제로 살펴보고자 한다. 이에 다음과 같은 연구모형과 연 구문제를 설정하였다.

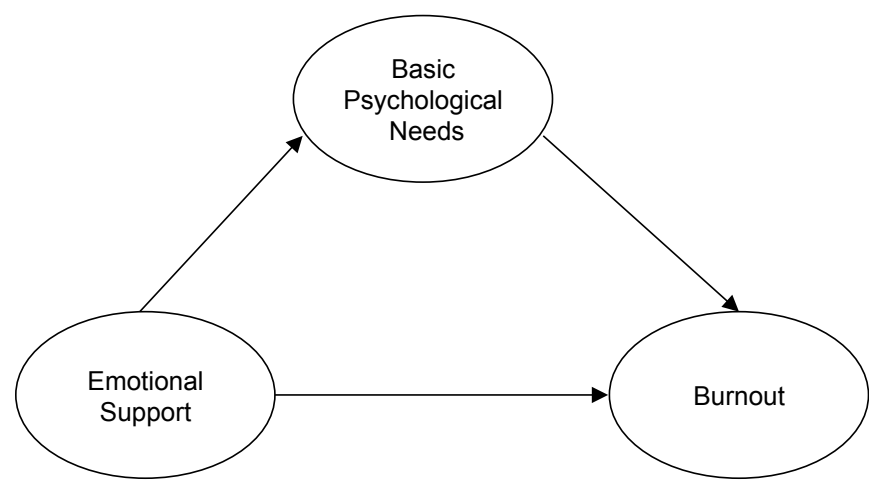

Figure 1. Model of the study.

\section{연구문제 1}

보육교사의 지각된 정서적 지지는 기본심리욕구를 매개로 소 진에 유의한 영향을 미치는가?

\section{Methods}

\section{연구대상}

연구대상은 대구.경북 지역 내 어린이집에 재직 중인 보육교 사 228 명이다.

Table 1에 나타난 바와 같이 보육교사의 연령은 40대가 103 명(45.2\%), 총 경력은 5년 이상의 경력이 128 명(56.2\%), 2-3년 제 졸업이 128 명 $(56.1 \%)$ 이며, 대학을 통한 자격증 취득이 159 명 (69.7\%), 민간 어린이집 근무가 98 명(43.0\%), 1 급 보육교사 자격 증 소지가 142 명(62.3\%), 기혼이 173 명(75.9\%)으로 가장 많았다.

자료는 자기 보고식 질문지법을 이용하여 수집하였으며 이 를 위해 사용된 연구의 척도는 다음과 같다.

\section{연구도구}

\section{소진}

Maslach와 Jackson (1981)이 개발한 소진 척도를 Kang (1996) 이 번안하고 타당도와 신뢰도를 검증한 MBI (Maslach Burnout 
Table 1

Characteristics of Participants

\begin{tabular}{|c|c|c|c|c|c|}
\hline Variables & Categories & $n(\%)$ & Variables & Categories & $n(\%)$ \\
\hline \multirow[t]{2}{*}{ Age } & Under 30 & $98(43)$ & Position & Head teacher & $28(12.3)$ \\
\hline & Over 40 & $130(57 \quad)$ & & Teacher & $199(87.7)$ \\
\hline \multirow[t]{5}{*}{ Total work experience } & 1 year or less & $19(8.3)$ & Type of daycare center & Public & $48(21.0)$ \\
\hline & Less than 2 to 3 years & $29(12.7)$ & & Workplace & $15(6.6)$ \\
\hline & Less than 3 to 4 years & $24(10.5)$ & & Social welfare organization & $21(9.2)$ \\
\hline & Less than 4 to 5 years & $28(12.3)$ & & Private & $98(43.0)$ \\
\hline & Over 5 years & $128(56.2)$ & & Family home care & $46(20.2)$ \\
\hline \multirow[t]{3}{*}{ Education level } & $\begin{array}{l}\text { Four-year } \\
\text { college or higher }\end{array}$ & $83(36.4)$ & Qualifications & Childcare teacher level 1 & $142(62.3)$ \\
\hline & $\begin{array}{l}\text { Two- or three- } \\
\text { year college graduate }\end{array}$ & $128(56.1)$ & & Childcare teacher level 2 & $66(28.9)$ \\
\hline & High school graduate & $17(7.5)$ & & Childcare teacher level 3 & $20(8.8)$ \\
\hline \multirow[t]{2}{*}{ Qualifying institution } & University & $159(69.7)$ & Marital status & Married & $173(75.9)$ \\
\hline & Teacher train ing center & $69(30.3)$ & & Single & $55(24.1)$ \\
\hline
\end{tabular}

Inventory)를 본 연구에 맞게 ‘학생’을 ‘원아’로 수정하여 사용하 였다. “나는 업무로 인해 몸과 마음이 지쳐있는 느낌이다.”, "나 는 교사가 된 후 사람들에 대해 무관심해졌다.” 등으로 이루어 진 각 문항의 응답방식은 매우 아니다(1점)에서, 매우 그렇다(5 점)의 5 점 척도로 측정하였다. 정서적 고갈 9 문항, 비인간화 4 문 항, 성취감 감소 8 문항 등 총 21 문항으로 구성된 총점의 범위는 21-105점이며, 부정적인 문항은 역 채점하여 총점을 산출하였 다. 점수가 높을수록 심리적 소진이 더 높은 것을 의미한다. 문 항 간 내적 합치도에 의한 신뢰도 Cronbach's $\alpha$ 는 정서적 고갈 .83 , 비인간화 .62, 성취감 감소 .67, 전체 .86으로 나타났다.

\section{정서적 지지}

직장 내에서 보육교사가 지각하는 정서적 지지를 측정하기 위 해 Shakespeare-Finch와 Obst (2011)가 개발한 이원 사회적 지지 (2-way social support)척도 중 정서적 지지 문항을 사용하였다. "내 삶의 어려움에 대해서 이야기할 누군가가 어린이집에 있 다.", "내가 힘이 들 때 기댈 수 있는 사람이 어린이집에 있다." 등으로 이루어진 각 문항의 응답방식은 매우 아니다(1점)에 서, 매우 그렇다(5점)의 5점 척도로 측정하였다. 7 문항으로 구 성된 총점의 범위는 7-35점이며, 점수가 높을수록 타인으로부 터 정서적 지지를 많이 제공받고 있음을 나타낸다. 정서적 지 지는 단일차원으로 구성된 문항이므로 구조방정식 모델 분석 을 위해 문항꾸러미를 만들어 '지지1(3문항)', '지지2(4문항)'의
하위척도를 구성하였다. 문항꾸러미(item parceling method)는 단일 척도에서 발생될 수 있는 추정모수의 증가에 따른 추정 오차의 문제를 해결하는 방법(Russel, Kahn, Spoth, \& Altmaier, 1998)이다. 문항 간 내적 합치도에 의한 신뢰도는 Cronbach's $\alpha$ 는 정서적 지지 1.85 , 정서적 지지 2.93 , 전체 .92로 나타났다.

\section{기본심리욕구}

자기결정성 이론에 근거하여 Ryan과 Deci (2002)의 기본심리욕 구 척도(Basic Psychological Need Scale [BPNS])를 M. Lee와 Kim (2008)이 번안, 타당화한 것을 수정하여 사용하였다. "나는 내 일을 진행하는 방법을 스스로 결정할 기회가 많지 않다." "나 는 다른 사람들에 의해 통제받고 억압을 받는다고 느낀다.” 등 으로 이루어진 각 문항의 응답방식은 매우 아니다(1점)에서, 매 우 그렇다(5점)의 5점 척도로 측정하였다. 자율성 6문항, 유능 성 6 문항, 관계성 6 문항 등 총 18 문항으로 구성된 총점의 범위 는 18-90점이며, 부정적인 문항은 역 채점하여 총점을 산출하 였다. 점수가 높을수록 기본심리욕구가 잘 충족되었음을 의미 한다. 문항 간 내적 합치도에 의한 신뢰도는 Cronbach's $\alpha$ 는 자 율성 .74, 유능성 .81, 관계성 .70, 전체 .84로 나타났다.

\section{연구절차}

대구경북지역 소재의 어린이집에서 보육교사로 재직 중이면 
Table 2

Means, Standard Deviations, and Correlations Among Variables

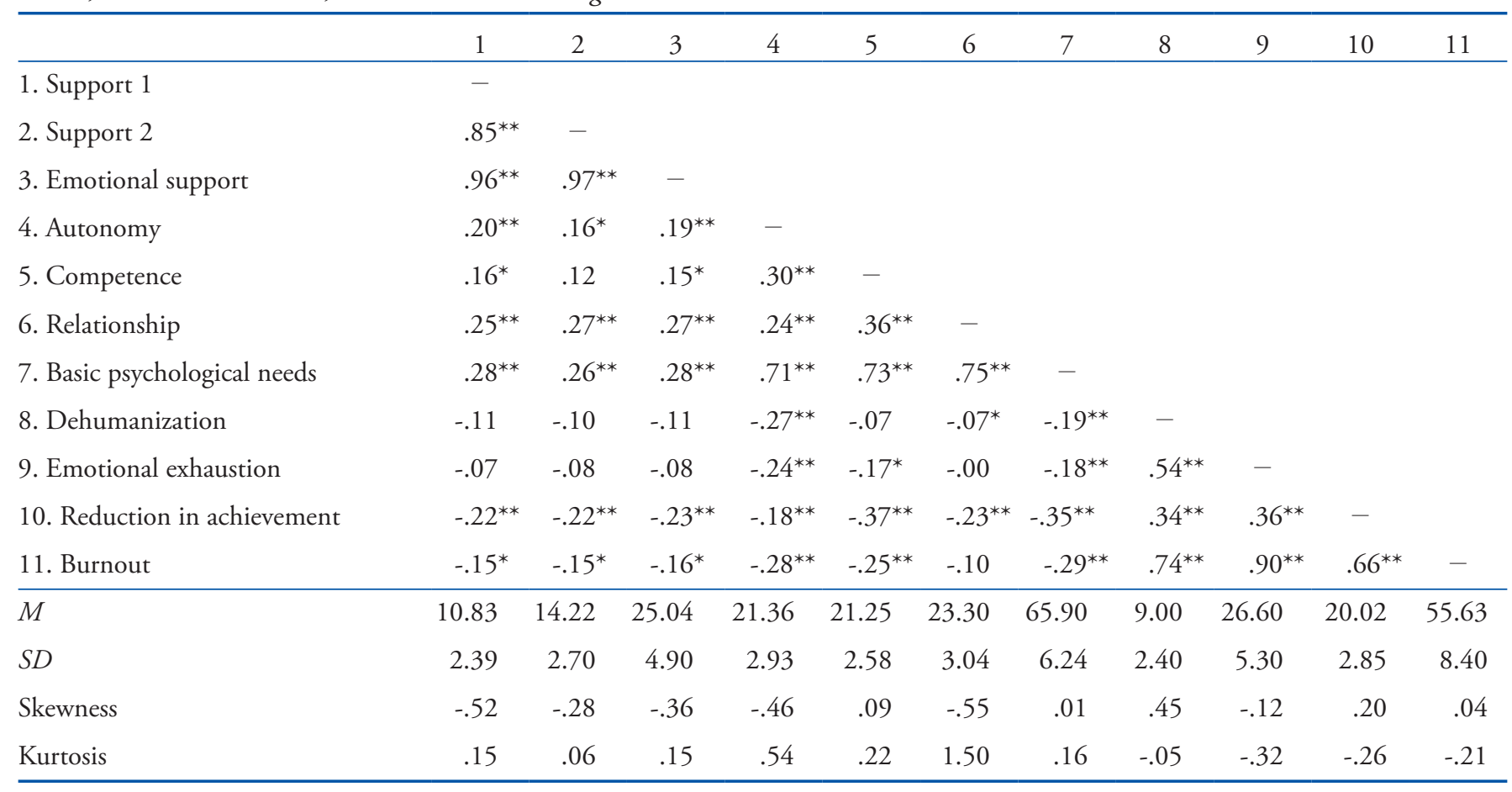

Note. $N=228$.

${ }^{*} p<.05 .{ }^{* *} p<.01$.

서, 승급교육이나 보수교육을 위해 보육교사 교육원을 찾은 보육교사들에게 질문지 조사를 부탁했다. 이를 위해 보육교 사 교육원으로부터 사전에 질문지 조사를 허락받았으며 자발 적으로 조사에 응한 보육교사들에게는 조사 동의서를 받았다. 질문지는 승급이나 보수교육이 시작되기 전에 연구자가 배부 했으며, 당일 귀가 시 연구자가 수거하였다. 총 250 부를 배부 했으며 회수된 질문지 중 결측 문항이 한 개라도 포함된 질문 지 또는 답변이 성실하게 이루어지지 않은 22 부의 질문지는 모두 제외하고 228 명의 질문지 자료만을 분석에 사용하였다.

\section{자료분석}

보육교사의 지각된 정서적 지지, 기본심리욕구, 소진 간 관계 를 경로모형을 통해 탐색하고자 한 이 연구는 구조방정식 모 형의 적합성을 규명하기 위해 SPSS 19.0 (IBM Co., Armonk, $\mathrm{NY}$ )의 평균, 표준편차, Pearson 상관계수를 사용했으며, Amos 24.0 (IBM Co., Armonk, NY) 프로그램을 통해 절대적합지수인 $\chi^{2}$, RMSEA과 중분적합지수인 TLI, CFI값을 살펴보았다. 그리 고 Bootstrapping절차를 이용하여 간접효과의 유의성을 살펴 보았다.

\section{Results}

\section{측정 변인들의 일반적 경향}

구조방정식 모형을 통해, 보육교사의 지각된 정서적 지지와 기본심리욕구, 소진 간 경로모형의 적합성을 살펴보기에 전에 관련 변인 간 상관관계 및 평균(표준편차), 왜도, 첨도 등의 기 술통계치를 살펴보았다.

Table 2에 나타난 바와 같이, 보육교사의 정서적 지지 평균 은 $25.04(S D=4.90), 2$ 개 지표 평균은 각각 $10.83(S D=2.39)$ 와 $14.22(S D=2.70)$ 로 나타났다. 기본심리욕구 평균은 65.90 $(S D=6.24)$ 이며, 하위 지표인 자율성의 평균은 $21.36(S D=$ $2.93)$, 유능성의 평균은 $21.25(S D=2.58)$, 관계성의 평균은 $23.30(S D=3.04)$ 로 나타났다. 소진 평균은 $55.63(S D=8.40)$ 이며 하위 지표인 비인간화의 평균은 $9.00(S D=2.40)$, 정서 적 고갈의 평균은 $26.60(S D=5.30)$, 성취감소의 평균은 20.02 $(S D=2.85)$ 로 나타났다. 한편 왜도와 첨도 값은 각각 기준값 이 3 과 10 미만 값이 나왔다. 이는 자료의 분포가 정규분포를 이루고 있음을 시사하는 것(Kline, 2005)이므로 최대우도추정 (maximum likelihood estimation)절차를 이용하여 모델의 적합 


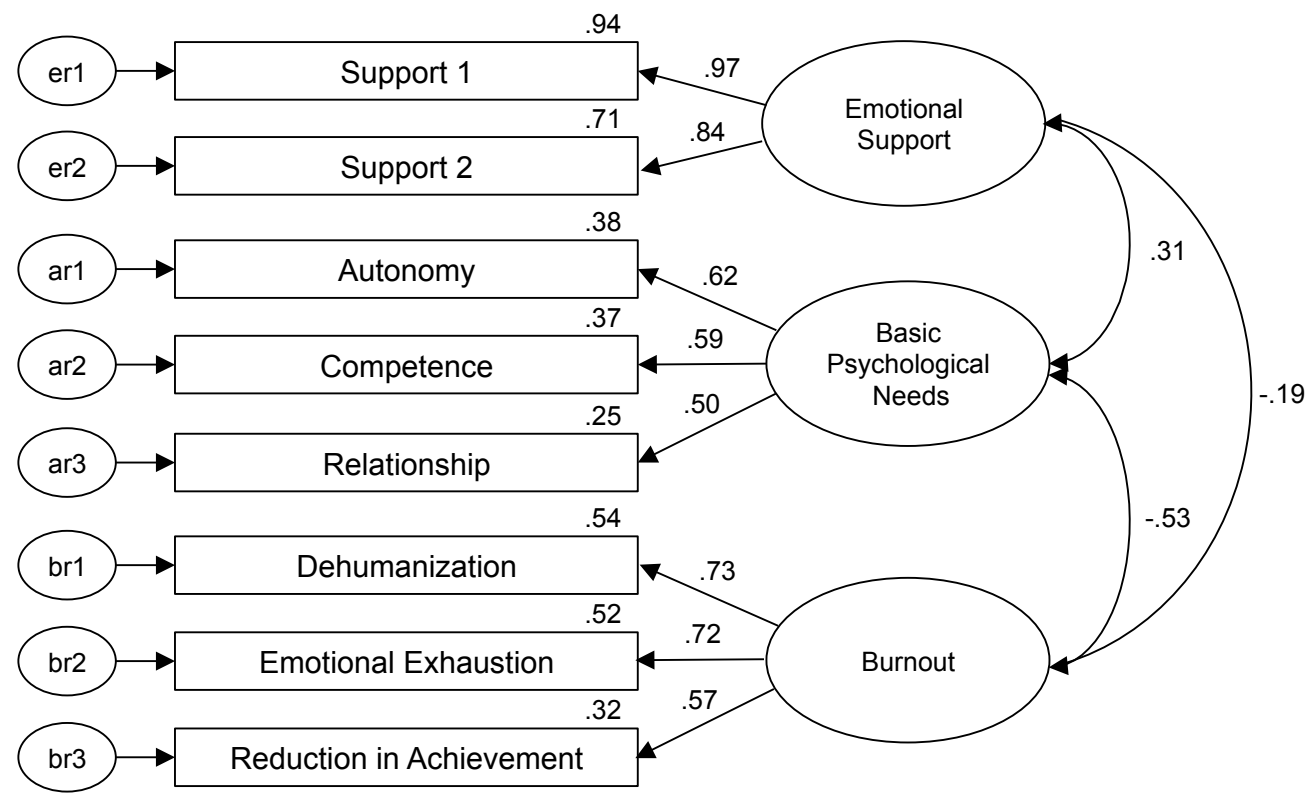

Figure 2. Confirmatory factor analysis model.

도와 모수치를 추정하기로 하였다.

\section{측정모형의 검증}

확인적 요인분석(confirmatory factor analysis)을 통해 잠재변수 로 사용된 보육교사의 지각된 정서적 지지, 기본심리욕구, 소 진의 측정변인들이 이론적 개념을 잘 반영하고 있는지를 검 토하였다. 최대우도추정법을 적용하여 측정모델의 적합도 (goodness of fit)와 모수치를 추정한 결과 Table 2에 나타난 바 와 같이 측정모델의 적합도는 $\chi^{2}=39.15(d f=17, p<.05)$, TLI $=.93, \mathrm{CFI}=.96, \mathrm{RMSEA}=.08$ 로 나타났다. 모형적합도를 나 타내는 RMSEA 평균이 .08 로 < .08 이하의 기준치(Browne $\&$ Cudeck, 1993)를 충족하며, 독립모형 대비 연구모형 적합도를 나타내는 TLI, CFI가 모두 > .90 이상의 기준(Kline, 2005)를 충 족하고 있는 것으로 나타났다. 이는 만족스러운 모형 적합도 임을 나타내는 것으로 연구의 측정모형이 타당함을 의미하는 것이다.

한편, Figure 2는 측정모델의 각 잠재변인과 측정 변인들 간 의 요인부하량 및 잠재변인들 간의 상관관계를 나타낸 것이다. 잠재변인들 간의 상호상관계수가 절대값 .19 .53 사이에서 모 두 유의미하게 나타났고, 각 잠재변인과 측정변인들 간 요인부 하량이 모두 .50 이상으로 나타났다. 이는 측정 변인들이 각 잠 재변인에 대해 수렴타당도가 있음을 의미하는 것이다.

\section{연구모형 분석}

보육교사의 지각된 정서적 지지와 기본심리욕구, 소진 간 경 로모형의 적합성을 살펴보기 위해 모든 경로가 설정된 부분 매개모델을 연구모형으로 설정하였다. 그리고 독립에서 종속 변인으로 직접 가는 경로를 제외한 완전 매개모델을 경쟁모 형으로 설정하였다. Table 3에 나타난 바와 같이 경쟁모형인 완전매개모델의 RMSEA의 값이 .07로 연구모형인 부분매개 모델의 RMSEA의 값 .08보다 좋은 적합도를 나타냈으며 TLI, $\mathrm{CFI}$ 의 값 또한 모두 > .90 의 값을 나타내었다. 이는 연구모형 인 부분매개모델보다 경쟁모형인 완전매개모델을 선정하는 것이 적합함을 의미하는 것이다. 구조모델 적합도 결과에 따 라 최종모델로 선정한 완전매개모델의 모수치를 추정하였다. 그 결과는 Figure 3 과 같으며, 모수치에 대한 통계적 유의성을 검증한 결과는 Tabel 3 과 같다.

Figure 3은 보육교사가 지각한 정서적 지지, 기본심리욕구, 소진 간 경로모형에서 보육교사가 지각한 정서적 지지와 소진 간 직접 관계가 형성되지 못한 완전매개모델로, 보육교사가 지각한 정서적 지지가 소진에 미치는 영향이 기본심리욕구를 매개로 한 간접 영향임을 나타내는 것이다.

이를 Table 4 를 통해 구체적으로 살펴보면 보육교사의 기본 심리욕구는 소진에 부적 영향을 유의하게 미치는 것으로 나타 났다 $(\beta=-.54, p<.001)$. 즉 보육교사의 소진은 기본심리욕구 가 충족될수록 낮은 것으로 나타났다. 보육교사가 지각한 정 
Table 3

Summary of Model Fit Statistics

\begin{tabular}{lcccccc}
\hline \multicolumn{1}{c}{ Model } & $\chi^{2}$ & $d f$ & $p$ & RMSEA & TLI & CFI \\
\hline Hypothetical path model & 39.15 & 17 & .05 & .08 & .93 & .96 \\
Modified path model & 39.23 & 18 & .05 & .07 & .93 & .96 \\
\hline
\end{tabular}

Note. $\chi^{2}=$ chi-square; RMSEA = root mean square error of approximation; TLI = tucker-lewis index; CFI = comparative fit index.

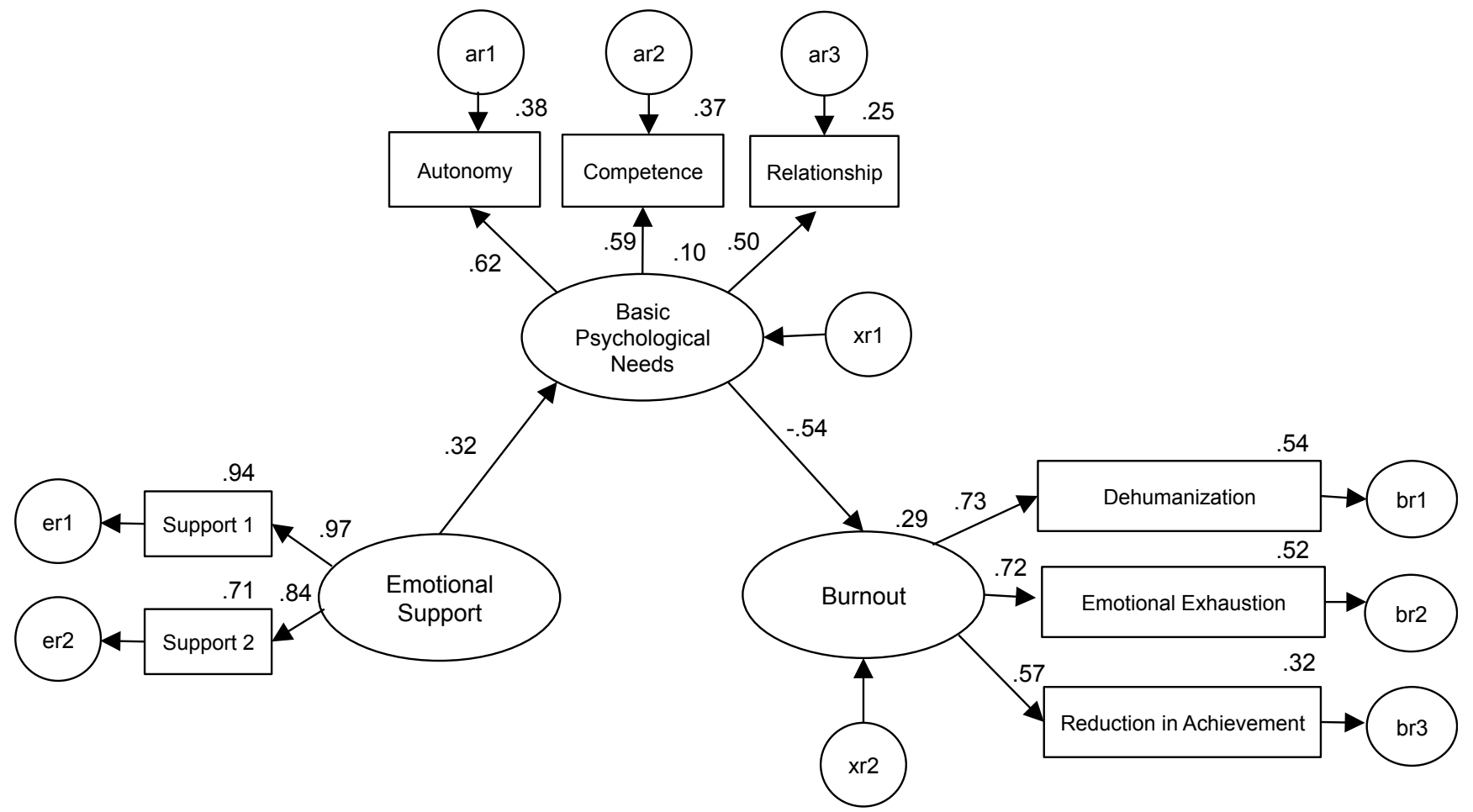

Figure 3. Final research model.

Table 4

Path Estimate of Final Research Model

\begin{tabular}{|c|c|c|c|c|c|c|}
\hline \multicolumn{3}{|c|}{ Pathway } & $\beta$ & $B$ & $S E$ & CR \\
\hline Basic psychological needs & $\rightarrow$ & Burnout & -.54 & -.51 & .12 & $-4.43^{* * *}$ \\
\hline Emotional support & $\rightarrow$ & Basic psychological needs & .32 & .27 & .08 & $3.15^{* *}$ \\
\hline Emotional support & $\rightarrow$ & Support 1 & .97 & 1.00 & & \\
\hline Emotional support & $\rightarrow$ & Support 2 & .84 & .99 & .03 & $24.93^{* * *}$ \\
\hline Basic psychological needs & $\rightarrow$ & Relationship & .50 & .81 & .17 & $4.91^{* * *}$ \\
\hline Burnout & $\rightarrow$ & Dehumanization & .73 & 1.00 & & \\
\hline Burnout & $\rightarrow$ & Emotional exhaustion & .72 & 2.25 & .31 & $7.22^{* * *}$ \\
\hline
\end{tabular}

Note. $N=228$.

${ }^{* *} p<.01 .{ }^{* * *} p<.001$. 
Table 5

Standardized Total Effect, Direct Effect and Indirect Effect in the Final Research Model

\begin{tabular}{lccc}
\hline \multicolumn{1}{c}{ Path } & Total effect & Direct effect & Indirect effect \\
\hline Emotional support $\rightarrow$ Burnout & $-.17^{* *}$ & & $-.17^{* *}$ \\
Basic psychological needs $\rightarrow$ Burnout & $-.54^{* *}$ & $-.54^{* *}$ & \\
Emotional support $\rightarrow$ Basic psychological needs & $.32^{* *}$ & $.32^{* *}$ & \\
\hline
\end{tabular}

Note. $N=228$.

${ }^{* *} p<.01$.

서적 지지는 기본심리욕구에 정적 영향을 유의하게 미치는 것 으로 나타났다 $(\beta=.32, p<.01)$. 이는 보육교사가 지각한 정서 적 지지가 클수록 기본심리욕구가 더 많이 충족되었음을 의미 하는 것이다.

보육교사의 지각된 정서적 지지가 기본심리욕구를 매 개로 소진에 미치는 간접 효과의 유의성을 살펴보기 위해 Bootstrapping을 실시하였다. 분석결과 Tabel 5에 나타난 바와 같이 간접 효과는 유의한 것으로 나타났다.

\section{Discussion}

$\mathrm{AMOS}$ 의 구조방정식 모형을 사용해 보육교사가 지각한 정서 적 지지가 기본심리욕구를 매개로 소진에 유의한 영향을 미치 는가를 살펴본 이 연구는 보육교사가 지각한 정서적 지지가 기본심리욕구를 완전매개로 소진에 유의한 영향을 미치고 있 음을 확인하였다. 이에 확인된 완전매개의 경로모형을 기반으 로 다음과 같은 세가지 세부 논의를 도출하였다.

첫째, 보육교사의 기본심리욕구는 소진에 부적 영향을 미 치고 있다는 점이다. 이와 같은 결과는 자율성, 유능성, 관계 성의 기본심리욕구가 잘 충족된 직장인의 경우 직무 활동에 서 낮은 소진을 나타났다고 보고한 연구결과(Deci et al., 2001; Ford et al., 2019; H.-H. Lee \& Hong, 2018; H. Oh et al., 2019)와 일치하는 것이다. 더불어 기본심리욕구의 충족이 잘 이루어진 근로자의 경우 직장에서 낮은 불안감, 높은 직무몰입을 보인 다는 연구결과(Deci et al., 2001; Van den Broeck, Ferris, Chang, $\&$ Rosen, 2016)를 지지하는 것이라 볼 수 있다. 기본심리욕구 는 개인적 성장, 공동체 기여와 같은 내재적 목표를 성취하도 록 하는 자기결정성의 원동력이다(Kasser \& Ryan, 1996). 따라 서 기본심리욕구가 잘 충족된 보육교사는 보육환경 변화에 따 른 업무 수행을 환경적 요구에 의해 달성 해야만 하는 의무나 책임으로 간주하기보다 능동적이며 자발적으로 해결해야 할 내용으로 평가하기 쉽다. 보육 업무에 대한 인식이나 평가가
자기결정성에 의한 자기성장 과정으로 평가될 수 있다는 점에 서 보육교사의 기본심리욕구의 충족은 소진을 조기 예방할 수 있는 개인 내적 자원으로 적극 고려될 수 있다.

둘째, 보육교사의 소진에 부적 영향을 미치는 기본심리욕 구는 사회적 관계망으로부터 제공되는 정서적 지지에 의해 정적 영향을 받는다는 점이다. 이러한 사실은 사회적 관계망 으로부터 제공된 사회적 지지가 자기결정성의 기본심리욕구 에 정적 영향을 미친다고 보고한 선행 연구 결과(Ryan \& Deci, 2000; Ryan \& Solky, 1996; Soenens \& Vansteenkiste, 2005; Yoon, 2015)와 유사한 것이다. 보육교사의 사회적 관계망 중 동료교 사나 원장 등 중요한 타인(significant others)들이 제공하는 공 감, 승인, 인정, 격려 등의 정서적 지지(Berndt \& Perry, 1986)는 자기결정성 이론의 기본심리욕구 충족 중 관계성 욕구를 충족 시키는 환경적 요소라 할 수 있다. 타인과 연결되어 있다는 감 정을 충족시키고 싶어하는 인간의 기본심리욕구는 타인과 상 호작용이 일어나는 사회적 관계망을 통해 해결될 수밖에 없 다. 이러한 점에서 어린이집 원장은 근무 과정에서 보육교사 가 정서적 지지를 체감할 수 있는 기회를 확장하는데 관심을 가질 필요가 있다.

셋째, 보육교사가 지각한 정서적 지지는 소진에 부적인 영 향을 미치고 있지만 이러한 영향은 자기결정성의 기본심리욕 구가 통제되었을 때 사라진다는 점이다. 보육교사의 소진에 미치는 정서적 지지의 영향이 기본심리욕구를 매개로 한 간 접 영향을 미친다는 사실은 보육교사의 소진에 더 큰 영향을 미치는 것은 기본심리욕구의 충족이라는 점을 시사한다. 이 는 사회적 관계망에서 제공되는 정서적 지지와 같은 환경 외 적 변인보다 자신의 행동을 스스로 주관하려는 자율성, 자신 의 능력이나 기술을 숙련있게 사용하거나 발전시키고자 하는 유능성, 그리고 사회에서 고립되지 않고 연결되고자 하는 관 계성을 충족하고자 하는 개인 내적 욕구의 충족 정도가 보육 교사의 소진을 예방하는데 더 큰 역할을 할 수 있음을 시사하 는 것이다. 이러한 시사는 보육교사의 소진을 사전에 관리하 고 미연에 예방하고자 할 때 기본심리욕구 충족에 초점을 둔 
프로그램 개발이 필요함을 의미하는 것이다. 사회적 관계망으 로부터 제공되는 정서적 지지에 비해 기본심리욕구가 보육교 사의 소진에 미치는 영향력은 상당하지만, 기본심리욕구는 사 회적 관계망으로부터의 정서적 지지에 의해 정적 영향을 받는 다는 점을 상기할 필요가 있다. 그런 점에서 정서적 지지는 보 육교사의 소진 예방에 있어 폄하될 수 없는 변인인 것이다. 어 린이집 운영 차원에서 원장은 교사 상호간 정서적 지지를 향 상시킬 수 있는 방안을 교사주도적 차원에서 구안해 볼 것을 제안할 수 있다. 교사주도에 의해 탐색되는 정서적 지지 향상 방안은 원장에 의해 계획되고 마련된 방안보다 높은 효용성 과 실천성을 가질 수 있기 때문이다. 한편 보육교사들은 교사 주도의 정서적 지지 향상 방안 탐색 과정에서 자율성, 유능성, 관계성의 기본심리욕구를 자연스럽게 충족할 수 있다. 교사가 주체가 되어 교사가 잘 할 수 있는 방법을 찾아가는 과정에서 자율성과 유능성을 경험할 수 있고, 함께 생각하고 상호 만족 할 수 있는 방안 탐색 과정에서 하나됨의 관계성을 확인할 수 있기 때문이다.

이 연구는 보육교사의 소진 예방에 도움이 될 수 있는 변인 을 환경 외적 변인과 개인 내적 변인을 통해 살펴보았다. 그리 고 완전매개의 경로모형 관계를 규명함으로써 보육교사의 소 진 예방을 위해 보육현장에서 보다 효과적인 방법을 구안할 수 있는 정보와 자료를 제공했다는 점에서 연구의 의의를 갖 는다. 그러나 이 연구에서 근무시간, 임금 등 보육교사의 소진 에 영향을 미치는 물리적 근무 환경 등에 관한 자료를 포함하 지 못함으로써 보육교사의 소진을 이해하는데 한계가 있다. 이러한 점은 이 연구의 결과를 보육현장에 적용할 때 주의해 야 할 부분이며, 이와 관련된 추후 연구에서 신중히 고려해야 할 부분이라 할 수 있다.

\section{Notes}

This article is a part of the first author's Master's thesis submitted in 2020, and was presented as a poster at the 2020 Annual Spring Conference of the Korean Association of Child Studies.

\section{Conflict of Interest}

The authors report no potential conflict of interest relevant to this study.

\section{Ethics Statement}

All procedures of this study were reviewed and approved by the institutional review board (CUIRB-2018-0026).

\section{References}

\section{In English}

Berndt, T., \& Perry, T. B. (1986). Children's perceptions of friendships as supportive relationships. Developmental Psychology, 22(5), 640-648. doi:10.1037/00121649.22.5.640

Browne, M. W., \& Cudeck, R. (1993). Alternative ways of assessing model fit. In K. A. Bollen \& J. S. Long (Eds.), Testing structural equation models (pp. 136-162). Newbury Park, CA: Sage.

Cobb, S. (1976). Social support as moderator of life stress. Psychosomatic Medicine, 38(5), 300-314. doi:10.1097/00006842197609000-00003

Cohen, S., \& Hoberman, H. (1983). Positive events and supports as buffers of life change stress. Journal of Applied Social Psychology, 13(2), 99-125.

Deci, E. L., \& Ryan, R. M. (1985). Intrinsic motivation and selfdetermination in human behavior. New York: Plenum Press.

Deci, E. L., \& Ryan, R. M. (2000). The "what" and "why" of goal pursuit: Human needs and the self-determination of behavior. Psychological Inquiry, 11(4), 227-268. doi:10.1207/S15327965PLI1104_01

Deci, E. L., Ryan, R. M., Gagné, M., Leone, D. R., Usunov, J., \& Kornazheva, B. P. (2001). Need satisfaction, motivation and well-being in the work organizations of a former eastern bloc country: A cross-cultural study of self-determination. Personality and Social Psychology Bulletin, 27(8), 930-942. doi:10.1177/0146167201278002

Dubow, E. F., \& Tisak, J. (1989). The relation between stressful life events and adjustment in elementary school children: The role of social support and social problem-solving skills. Child Development, 60(6), 1412-1423. doi:10.1111/j.14678624.1989.tb04013.x

Ford, T. G., Olsen, J., Khojasteh, J., Ware, J., \& Urick, A. (2019). The effects of leader support for teacher psychological needs on teacher burnout, commitment, and intent to leave. Journal of Educational Administration, 57(6), 615-634. doi:10.1108/JEA-09-2018-0185

Freudenberger, H. J. (1974). Staff-burnout. Journal of Social Issues, 30(1), 159-165. doi:10.1111/j.1540-4560.1974.tb00706.x 
House, J. S. (1981). Work stress and social support. Boston, MA: Addison-Wesley.

Kasser, T., \& Ryan, R. M. (1996). Further examining the American dream: Differential correlates of intrinsic and extrinsic goals. Personality and Social Psychology Bulletin, 22(3), 280287. doi:10.1177/0146167296223006

Kline, R. B. (2005). Principles and practice of structural equation modeling (2nd ed.). New York: The Guilford Press.

Maslach, C., \& Jackson, S. E. (1981). The measurement of experienced burnout. Journal of Organizational Behavior, 2(2), 99-113. doi:10.1002/job.4030020205

Russell, D. W., Kahn, J. H., Spoth, R., \& Altmaier, E. M. (1998). Analyzing data from experimental studies: A latent variable structural equation modeling approach. Journal of Counseling Psychology, 45(1), 18-29. doi:10.1037/00220167.45.1.18

Ryan, R. M., Connell, J. P., \& Deci, E. L. (1985). A motivational analysis of self-determination and self-regulation in education. In R. Ames \& C. Ames (Eds.), Research on motivation in education: The classroom milieu (pp. 13-51). New York: Academic Press.

Ryan, R. M., \& Deci, E. L. (2000). Self-determination theory and the facilitation of intrinsic motivation, social development, and well-being. American Psychology, 55(1), 68-78. doi:10.1037/0003-066X.55.1.68

Ryan, R. M., \& Deci, E. L. (2002). An overview of selfdetermination theory: An organismic-dialectical perspective. In E. L. Deci \& R. M. Ryan (Eds.), Handbook of self-determination research (pp.3-33). Rochester, NY: University of Rochester Press.

Ryan, R. M., \& Solky J. A. (1996). What is supportive about social support? On the psychological needs for autonomy and relatedness. In G. R. Pierce, B. R. Sarason, \& I. G. Sarason (Series Eds.), Handbook of social support and the family (pp. 249-267). New York: Plenum Press.

Shakespeare-Finch, J., \& Obst, P. L. (2011). The development of the 2-way social support scale: A measure of giving and receiving emotional and instrumental support. Journal of Personality Assessment, 93(5), 483-490. doi:10.1080/00223 891.2011 .594124

Soenens, B., \& Vansteenkiste, M. (2005). Antecedents and outcomes of self-determination in 3 life domains: The role of parents' and teachers' autonomy support. Journal of Youth and Adolescence, 34, 589-604. doi:10.1007/s10964005-8948-y

Thoits, P. A. (1982). Conceptual, methodological, and theoretical problems in studying social support as a buffer against life stress. Journal of Health and Social Behavior, 23(2), 145159. doi: $10.2307 / 2136511$

Van den Broeck, A., Ferris, D. L., Chang, C.-H., \& Rosen, C.
C. (2016). A review of self-determination theory's basic psychological needs at work. Journal of Management, 42(5), 1195-1229. doi:10.1177/0149206316632058

Van den Broeck, A., Vansteenkiste, M., De Witte, H., \& Lens, W. (2008). Explaining the relationships between job characteristics, burnout, and engagement: The role of basic psychological need satisfaction. Work \& Stress, 22(3), 277294. doi:10.1080/02678370802393672

\section{In Korean}

Choi, M.-S. (2009). A study on the self-determination motivation of preservice kindergarten teachers: Thinking style, social support. The Journal of Korea Open Association for Early Childhood Education, 14(1), 201-223.

Choi, S. (2015). The influence of working environment of schools on burnout and engagement among teachers-The mediating effect of automous motivation-(Master's thesis). Retrieved from http://www.riss.kr/link?id=T12811132

Choi, Y.-Y., \& Shim, S.-Y. (1999). Perceptions of the work environment and burnout in korean early childhood educators. Korea Journal of Child Care and Education, 19, 133-148.

Joung, S. H., Choi, Y. M., \& Lee, H. Y. (2013). The influence of teacher efficacy and emotional support on the burnout of infant nursing teachers. Journal of Future Early Childhood Education, 20(4), 193-215.

Kang, H. G. (1996). Analysis of relationship between specificities and factors by job stresses of the teachers in normal and special education school (Doctoral dissertation). Retrieved from http://www.riss.kr/link?id=T12078808

Kim, Y.-M. (2003). A study on burnout and social support among early childhood teachers. Korea Journal of Child Care and Education, 34, 111-127.

Kwon, J. Y., Chung, M., \& Park, S. K. (2013). The relations between organizational characteristics of kindergarten and burnout of teachers. Early Childhood Education Research \& Review, 17(5), 251-266.

Lee, H.-H., \& Hong, J.-Y. (2018). The mediating effect of a basic psychological needs and perceived organizational support in the relationship between school counselor's job stress and burnout. Korea Journal of Counseling, 19(2), 173-194. doi:10.15703/kjc.19.2.201804.173

Lee, H.-S., \& Lee, H.-K. (2011). The relation between adult attachment and burnout in novice counselors: The mediation effect of basic psychological needs satisfaction. Korean Journal of Counseling, 12(5), 1433-1449. Retrieved from http://www.riss.kr/link?id=A99780077

Lee, M., \& Kim, A. (2008). Development and construct validation of the basic psychological needs scale for Korean 
adolescents: Based on the self-determination. Korean Journal of Social and Personality Psychology, 22(4), 157-174. doi:10.21193/kjspp.2008.22.4.010

Min, H.-Y. (2010). The relationship between depression, colleagues/ supervisor's emotional support levels and burnout experienced by teachers in kindergartens and childcare centers. Korean Journal of Child Studies, 31(4), 1-14.

Oh, H., Lee, K., \& Kim, H. (2019). Motivation profiles from self-determination theory: Using latent profile analysis in term of a person-centered approach. Korean Journal of Resources Development, 22(3), 177-208. doi:10.24991/ KJHRD.2019.09.22.3.177

Oh, S.-J., \& Choi, J.-A. (2016). Effects of childcare teachers' collective self-esteem on burnout. Journal of Parent Education, 8(2), 185-200.

Park, N.-S., \& Song, S.-M. (2019). The influence of childcare teacher's self-care on teacher-child interaction: The mediating effect of psychological burnout. Early Childhood Education Research \& Review, 23(6), 105-124. doi:10.32349/ ECERR.2019.12.23.6.105

Song, M. (2015). Structural equation modeling of social support, ego-resilience and burnout of childcare teachers: Mediating effects of ego-resilience and group differences by marital status. Early Childhood Education Research, 35(6), 377-396. doi:10.18023/kjece.2015.35.6.018

Yoon, C.-H. (2015). The mediating effect of basic psychological needs on the relation of perceived social support and high school students' career identity: A self-determination theory approach. Asian Journal of Education, 16(4), 129-154. doi:10.15753/aje.2015.12.16.4.129

\section{ORCID}

$\begin{array}{ll}\text { Yun Ok Choi } & \text { http://orcid.org/0000-0002-3753-3332 } \\ \text { Ha Young Min } & \text { http://orcid.org/0000-0002-0376-2735 }\end{array}$

Received August 28, 2020

Revision received October 9, 2020

Accepted November 17, 2020 